\begin{tabular}{|l|l|l|l|l|l|l|l|l|l|}
\hline \multirow{2}{*}{ SPi } & \multicolumn{3}{|l|}{ Journal Code: } & \multicolumn{2}{|l|}{ Article ID } & Dispatch: 29.07.11 & $\begin{array}{l}\text { CE: Chutvica Alkasih } \\
\text { B. Jonsewar }\end{array}$ \\
\cline { 2 - 7 } & P & S & T & 5 & 0 & 0 & & No. of Pages: 3 & ME:
\end{tabular}

\title{
10 Years with ICH E10: Choice of Control Groups
}

\section{Frank W. Rockhold ${ }^{\mathrm{a} *}$ and Gregory Enas ${ }^{\mathrm{b}}$}

\section{INTRODUCTION}

ICH E10: Choice of Control Group in Clinical Trials, hereafter referred to as E10, was written as a follow-on document to ICH E9 [1]. Its primary purpose was to provide a comprehensive review of all types of controls that could be used in clinical trials; however, it is most well known for its discussions of 'non-inferiority (NI) designs' (a term coined in ICH E9), and its introduction of the terms 'assay sensitivity' and 'historical sensitivity to drug effects' into the clinical trial lexicon. Although it is true that much of the motivation was to better define the characteristics of the NI trials, ironically this only occupies 2.5 pages of a 30-page document. Although it created a common language for the discussion of such trials, it did leave some of the critical issues (e.g., choice of margin) unresolved and as such has led to some significant controversy over the use of such designs in the approval of new drugs [2]. As such, it has not been as widely accepted as a successful teaching tool as was the case for ICH E9, as noted in a companion article [3].

The purpose of this viewpoint is to acknowledge the successes and issues around the use of E10 since its inception 10 years ago and make recommendations on the way forward.

\section{GEOGRAPHIC IMPACT}

E10 achieved several important purposes globally. It brought to light the inherent complexities in selecting a control group for clinical trials, especially in situations where a placebo control might be considered unethical. What the guideline reflected was a drive for more active controlled trials to demonstrate the superiority of new drugs in a move to get away from the 'me-too' era. The drive for the use of active controls has long been a focus of European and Japanese regulators for this reason, whereas the US FDA was far more focused on the use of placebo trials. Thus in the true spirit of $\mathrm{ICH}, \mathrm{E} 10$ tried to bring together potentially disparate views of the design of trials.

The use in E10 of safety trials was actively discussed at the time of the writing of the document, but, as noted in the next section, the concept is now taking hold, and perhaps in the future we may see combination designs of superiority or NI for efficacy, and NI for safety!

The creation of a common language spawned a number of regulatory guidance documents and international publications, including a recent review in China [4]. The debate will undoubtedly be renewed when the draft of the FDA Guidance on NI trials is finalized [5].

Some of the aforementioned controversy about NI trials is that new treatments were sometimes shown to be non-inferior to active controls of marginal initial efficacy. The actual effect of each successive new treatment may shrink to zero as the margins got slowly closer to NI to placebo. The term 'bio-creep' was introduced to define this phenomenon [6]. If the spirit of the $\mathrm{NI}$ approach was implemented, and one compared the new treatment to the best available treatment, then such trials would quickly become difficult to run as the margins would shrink for new treatments.

\section{SCIENTIFIC IMPACT OF ICH - E10}

First and foremost, E10 was the foundation for regulatory guidance issued by both FDA and EMA on the topic of NI trials [7-9]. Though E10 discusses NI trials, and the clinical and statistical literature is replete with publications covering this topic, resolution of major issues with NI trials has not been obtained. The FDA draft guidance of March 2010, for example, recommends that the fixed margin method be used to design and analyze the data from a $\mathrm{NI}$ trial (ref). The FDA's recommendation has been called into question by industry statisticians who defend the use of the synthetic method to control the Type 1 error rate associated with the $\mathrm{NI}$ null hypothesis $[10,11]$. Though E10 discusses the use of a fixed margin, it does not discuss data analysis methodologies. Analysis of a fixed-margin design will control the Type 1 error rate for that study alone. In contrast, the synthetic method uses both the historical data from the placebo-controlled studies ( which purport to demonstrate that the current control is in fact 'active'), and the data from the current active controlled study to determine $\mathrm{NI}$, controlling the Type 1 error rate across all these studies [12-14].

Though E10 states that most active-controlled trials are NI trials, this assumption is changing because of the recent advent of

${ }^{a}$ GlaxoSmithKline R\&D, Research Triangle Park, NC, USA

${ }^{b}$ Lilly Research Laboratories, Indianapolis, IN

*Correspondence to: Frank W. Rockhold, 5 Moore Drive, RTP, GlaxoSmithKline R\&D, Research Triangle Park, NC, USA.

E-mail: Frank.w.rockhold@gsk.com 


\section{Pharmaceutical Statistics}

comparative effectiveness studies seeking to demonstrate superior outcomes. There are a number of reasons that more superiority studies are being conducted using an active control. In many life-threatening or seriously morbid conditions when approved therapies are available, it is often viewed as unethical to test single agent therapy against a (putative) placebo. Investigators either have to resort to add-on treatment comparisons, or head to head versus the approved therapy. Likewise, in conditions where placebo studies have typically been used, there is a growing need from many stakeholders, prescribers and payers included, to know which of multiple therapies is best for a condition. Placebo controlled studies don't provide that information and comparative effectiveness superiority studies are necessary. A broader concern about benefit-risk comparisons across a pharmacologic class or other alternatives has produced a driving need for large active controlled studies. To answer the question 'which one is best' requires that one demonstrate the superiority of at least one of the drugs under study relative to overall benefit-risk. However, $\mathrm{NI}$ is often a legitimate additional goal of these studies, and E10 has provided the impetus for thoughtful design and analysis of these often large and expensive studies. E10 will continue to guide development of these 'gold-standard' randomized, controlled trials even as observational database studies are becoming more prevalent to answer 'what should I prescribe or pay for' types of questions.

E10 has forced investigators to be much more rigorous and thoughtful about a number of statistical issues associated with $\mathrm{NI}$ studies [15-17]. In particular, the twin topics of assay sensitivity and constancy of effect were discussed extensively and remain the bedrock concerns with $\mathrm{NI}$ trials. Assay sensitivity requires that the current study be capable of differentiating the experimental and active control if experimental was in fact inferior to active control Likewise, the constancy assumption requires that the relationship between active control and placebo is reliably estimated from historical studies. These are the assumptions that must be made when the current study is conducted without a placebo control group. These issues are manifested in a number of different topics that E10 forces one to consider, including:

- Hypothesis testing framework with appropriate null and alternative hypotheses under a nested family of tests $[18,19]$

- Establishment of the fixed margin based on estimation of active-control effect from multiple historical studies $[20,21]$

- Minimization of 'bias towards no-difference' resulting from non-adherence, treatment withdrawal, missing data, protocol deviations, and 'bio-creep' $[6,22]$

- Appropriate patient population to analyze (e.g., Intent-to-treat versus Per-Protocol) [23]

- Study designs with active and placebo controls [24]

The literature is starting to be populated with case studies showing how these issues are being addressed by regulatory agencies [25]. Much of this effort has been within the regulatory agencies and has facilitated scientific discussion between sponsors and regulators. NI trials have often been held to public scrutiny as they form the basis for significant applications for marketing approval.

Likewise, E10 has spawned a whole new conversation regarding the demonstration of safety or establishment of 'no harm'. In this situation, one desires to demonstrate NI with an 'inactive' or 'safe' control (e.g., placebo). The recent FDA guidance on cardiovascular risk assessment for drugs intended to treat patients with Type 2 diabetes is an example [26]. One must rule out an unacceptably high incidence of risk. In this case, the FDA has established by fiat what the fixed margin should be both prior to and following market authorization. Pre-market demonstration of similarity to a putatively safe agent will typically be based on a meta-analysis of all evidence from the Phase 3 trials contained in the new drug application. Post-market safety will usually require a dedicated cardiovascular outcomes study showing $\mathrm{NI}$ (if not superiority) with placebo or a marketed agent.

\section{CONCLUSION}

ICH E10 helped create common language around the design of randomized controlled clinical trials, with an emphasis on active controlled trials. Although it did not deal with all the issues, it did create the infrastructure and language for the debate and numerous spinoff documents have been created. Because of the number of issues being currently debated, an update of the document does not make sense at this time. We can look forward to the resolution of the issues of margin and choice of which active control to use, and once some consensus has been achieved, create a parallel ICH guidance. In spite of the inherent complexities of these designs, it is likely that the use of $\mathrm{NI}$ designs will continue for its use in safety trials and as placebo designs become more and more difficult to execute. Thus continued perseverance to solve these issues is essential.

\section{REFERENCES}

[1] ICH E10 2000. Choice of control group in clinical trials. Available at URL: http://www.ich.org/LOB/media/MEDIA486.pdf [14 May2011].

[2] Ross B. The FDA and the case for Ketek. New England Journal of Medicine April 19 2007; 356:1601-1604.

[3] Rockhold FW, Ruberg SJ. ICH E9 reflections and considerations. Pharmaceutical Statistics 2 September 2008.

[4] Hou Y, Wu X-Y, Li K. Issues on the selection of non-inferiority margin in clinical trials. Chinese Medical Journal 2009; 122(4):466-470.

[5] FDA Guidance for Industry, Non Inferiority Clinical Trials - Draft Guidance. Available at URL: http://www.fda.gov/downloads/ Drugs/GuidanceComplianceRegulatoryInformation/Guidances/ UCM202140.pdf [March 2010].

[6] Everson-Stewart S, Emerson S. Biocreep in Non-Inferiority Trials. Q5 Statistics in Medicine 30 November 2010; 29(27):2769-2780.

[7] Temple R. Policy Developments in Regulatory Approval. Statistics in Medicine 2002; 21:2939-2948.

[8] Committee for Proprietary medicinal Products, CPMP/EWP/482/99 London, 27 July 2000.

[9] Temple R. Guidance for Industry Non-Inferiority Clinical Trials, March 2010

[10] Hung James HM, Wang SJ. Comment on "PISC Expert Team White Paper: Toward a Consistent Standard of Evidence When Evaluating the Efficacy of an Experimental Treatment From a Randomized Active-Controlled Trial". Statistics in Biopharmaceutical Research November 2010; 2(4).

[11] Peterson P, Carroll K, Chuang-Stein C, Ho YY, Jiang Q, Gang L, Sanchez M, Sax R, Wang Y-C, Snapinn S. Response. Statistics in Biopharmaceutical Research November 2010; 2(4).

[12] Hung James HM, Wang SJ, O'Neill R. Challenges and Regulatory Experiences with Non-inferiority Trial Design Without Placebo Arm. Biometrical Journal 2009; 51(2):324-334.

[13] Snapinn S, Jiang Q. Controlling the Type 1 Error Rate in NonInferiority Trials. Statistics In Medicine 2007. DOI: 10.1002/sim.3072.

[14] Snapinn S, Jiang Q. Preservation of effect and the regulatory approval of new treatments on the basis of non-inferiority trials. Statistics In Medicine 2007. DOI: 10.1002/sim.3073.

[15] Fleming T. Current issues in non-inferiority trials. Statistics In Q10 Medicine 2007. DOI: 10.1002/sim.2855. 
[16] Fleming T. COMMENTARY comments on current issues in noninferiority trials. Statistics In Medicine 2008; 27:333-342.

[17] D'Agostino RB, Sr., Massaro JM, Sullivan LM. Non-inferiority trials: design concepts and issues-the encounters of academic consultants in statistics. Statistics In Medicine 2003; 22:169-186.

[18] $\mathrm{Ng} \mathrm{TH}$. Noninferiority hypotheses and choice of noninferiority margin. Statistics In Medicine 2008. DOI: 10.1002/sim.3367.

[19] $\mathrm{Ng} \mathrm{TH}$. Issues of simultaneous tests for noninferiority and superiority. Journal of Biopharmaceutical Statistics 2003; 13(4):629-639.

[20] Gao P, Ware JH. Assessing non-inferiority: a combination approach. Statistics In Medicine (in press). DOI: 10.1002/sim.2938.

[21] Carroll KJ. Active-controlled, non-inferiority trials in oncology: arbitrary limits, infeasible sample sizes and uninformative data analysis. Is there another way? Pharmaceutical Statistics (in press). DOI: 10.1002/pst.218.
[22] Julious S, Wang SJ. How biased are indirect comparisons, particularly when comparisons are made over time in clinical trials. Drug Information Journal 2008; 42:625-633.

[23] Rohemel J, Pigeot I. A Comparison of multiple testing procedures for the gold standard non-inferiority trial. Journal of Biopharmaceutical Statistics 2010; 20(5):911-926.

[24] Wiens $B L$, Zhao $W$. The role of intention to treat in analysis of noninferiority studies. Clinical Trials 2007; 4:286-291.

[25] Sorbello A, Komo S, Valappil T. Noninferiority margin for clinical trials of antibacterial drugs for nosocomial pneumonia. Drug Information Journal 2010; 44:165-176.

[26] Guidance for Industry - Diabetes Mellitus - Evaluating Cardiovascular Risk in New Antidiabetic Therapies to Treat Type 2 Diabetes, FDA Division of Metabolism and Endocrinology Products in the Center for Drug Evaluation and Research, 2008. 


\section{Author Query Form}

\section{Journal: Pharmaceutical Statistics}

\section{Article: pst_500}

Dear Author,

During the copyediting of your paper, the following queries arose. Please respond to these by annotating your proofs with the necessary changes/additions.

- If you intend to annotate your proof electronically, please refer to the E-annotation guidelines.

- If you intend to annotate your proof by means of hard-copy mark-up, please refer to the proof mark-up symbols guidelines. If manually writing corrections on your proof and returning it by fax, do not write too close to the edge of the paper. Please remember that illegible mark-ups may delay publication.

Whether you opt for hard-copy or electronic annotation of your proofs, we recommend that you provide additional clarification of answers to queries by entering your answers on the query sheet, in addition to the text mark-up.

\begin{tabular}{|c|c|c|}
\hline Query No. & Query & Remark \\
\hline Q1 & AUTHOR: Please define EMA. & \\
\hline Q2 & $\begin{array}{l}\text { AUTHOR: Please check if provided address for the corresponding } \\
\text { author is correct. }\end{array}$ & \\
\hline Q3 & AUTHOR: Please check added page range. & \\
\hline Q4 & $\begin{array}{l}\text { AUTHOR: If this reference has now been published online, please } \\
\text { add relevant year/DOI information. If this reference has now been } \\
\text { published in print, please add relevant volume/issue/page/year } \\
\text { information. }\end{array}$ & \\
\hline Q5 & AUTHOR: Please check authors name. & \\
\hline Q6 & AUTHOR: Please provide page range. & \\
\hline Q7 & AUTHOR: Please check author names. & \\
\hline Q8 & AUTHOR: Please provide complete bibliographic details. & \\
\hline Q9 & $\begin{array}{l}\text { AUTHOR: If this reference has now been published online, please } \\
\text { add relevant year/DOI information. If this reference has now been } \\
\text { published in print, please add relevant volume/issue/page/year } \\
\text { information. }\end{array}$ & \\
\hline Q10 & $\begin{array}{l}\text { AUTHOR: If this reference has now been published online, please } \\
\text { add relevant year/DOI information. If this reference has now been } \\
\text { published in print, please add relevant volume/issue/page/year } \\
\text { information. }\end{array}$ & \\
\hline Q11 & AUTHOR: Year was provided please check. & \\
\hline
\end{tabular}




\section{USING E-ANNOTATION TOOLS FOR ELECTRONIC PROOF CORRECTION}

\section{Required Software}

Adobe Acrobat Professional or Acrobat Reader (version 7.0 or above) is required to e-annotate PDFs. Acrobat 8 Reader is a free download: http://www.adobe.com/products/acrobat/readstep2.html

Once you have Acrobat Reader 8 on your PC and open the proof, you will see the Commenting Toolbar (if it does not appear automatically go to Tools>Commenting>Commenting Toolbar). The Commenting Toolbar looks like this:

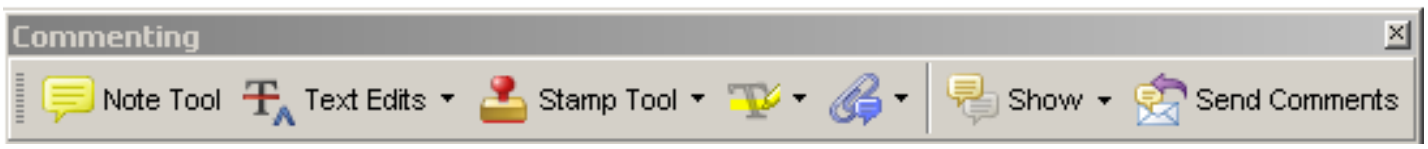

If you experience problems annotating files in Adobe Acrobat Reader 9 then you may need to change a preference setting in order to edit.

In the "Documents" category under "Edit - Preferences", please select the category 'Documents' and change the setting "PDF/A mode:" to "Never".

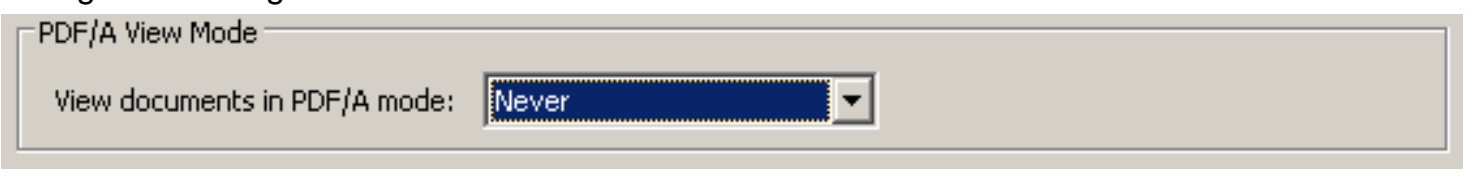

\section{Note Tool - For making notes at specific points in the text}

Marks a point on the paper where a note or question needs to be addressed.

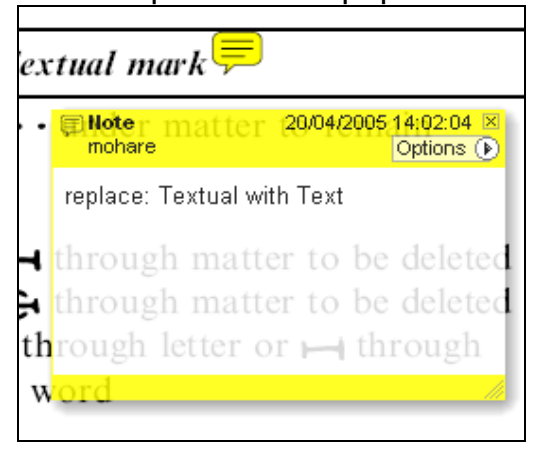

\section{How to use it:}

1. Right click into area of either inserted text or relevance to note

2. Select Add Note and a yellow speech bubble symbol and text box will appear

3. Type comment into the text box

4. Click the $X$ in the top right hand corner of the note box to close.

\section{Replacement text tool - For deleting one word/section of text and replacing it}

Strikes red line through text and opens up a replacement text box.

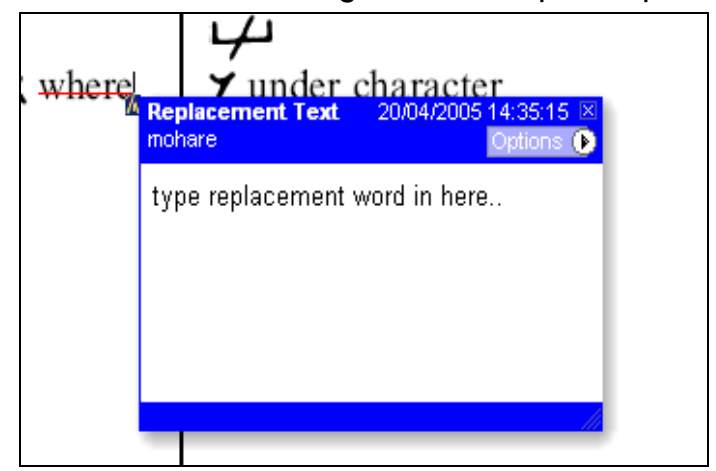
How to use it:
1. Select cursor from toolbar
2. Highlight word or sentence
3. Right click
4. Select Replace Text (Comment) option
5. Type replacement text in blue box
6. Click outside of the blue box to close

\section{Cross out text tool - For deleting text when there is nothing to replace selection}

Strikes through text in a red line.

\begin{tabular}{|l|}
\hline substitute part of one or \\
more word(s) \\
Change to italies \\
Change to capitals \\
Change to small capitals \\
\hline
\end{tabular}
How to use it:
1. Select cursor from toolbar
2. Highlight word or sentence
3. Right click
4. Select Cross Out Text 


\section{WILEY-BLACKWELL}

Approved tool - For approving a proof and that no corrections at all are required.

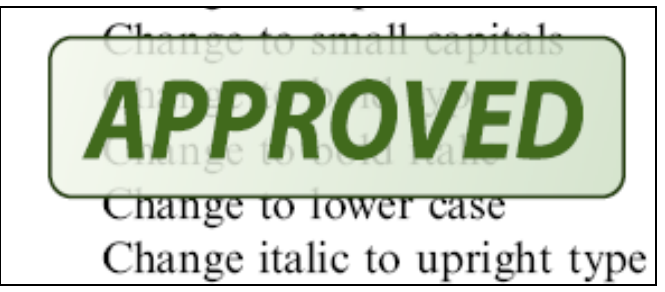

\section{How to use it:}

1. Click on the Stamp Tool in the toolbar

2. Select the Approved rubber stamp from the 'standard business' selection

3. Click on the text where you want to rubber stamp to appear (usually first page)

Highlight tool - For highlighting selection that should be changed to bold or italic. Highlights text in yellow and opens up a text box.

\begin{tabular}{|c|c|}
\hline & \\
\hline puble quotation & (As above) \\
\hline phen $\begin{array}{c}\text { Highlight } \\
\text { mohare }\end{array}$ & $\begin{array}{l}\text { 20:04:2005 14:45:47 } x \\
\text { Options (i) }\end{array}$ \\
\hline N par & \\
\hline parą & \\
\hline $\mathrm{se}$ & \\
\hline$p$ & \\
\hline ace b & \\
\hline
\end{tabular}

\section{How to use it:}

1. Select Highlighter Tool from the commenting toolbar

2. Highlight the desired text

3. Add a note detailing the required change

Attach File Tool - For inserting large amounts of text or replacement figures as a files. Inserts symbol and speech bubble where a file has been inserted.

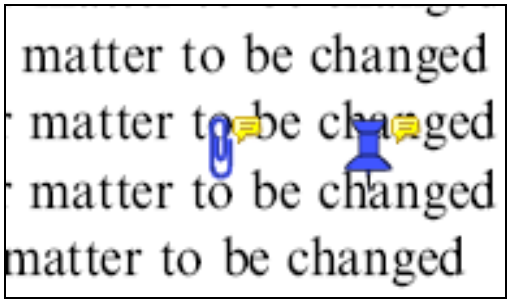

How to use it:

1. Click on paperclip icon in the commenting toolbar

2. Click where you want to insert the attachment

3. Select the saved file from your PC/network

4. Select appearance of icon (paperclip, graph, attachment or tag) and close

\section{Pencil tool - For circling parts of figures or making freeform marks}

Creates freeform shapes with a pencil tool. Particularly with graphics within the proof it may be useful to use the Drawing Markups toolbar. These tools allow you to draw circles, lines and comment on these marks.

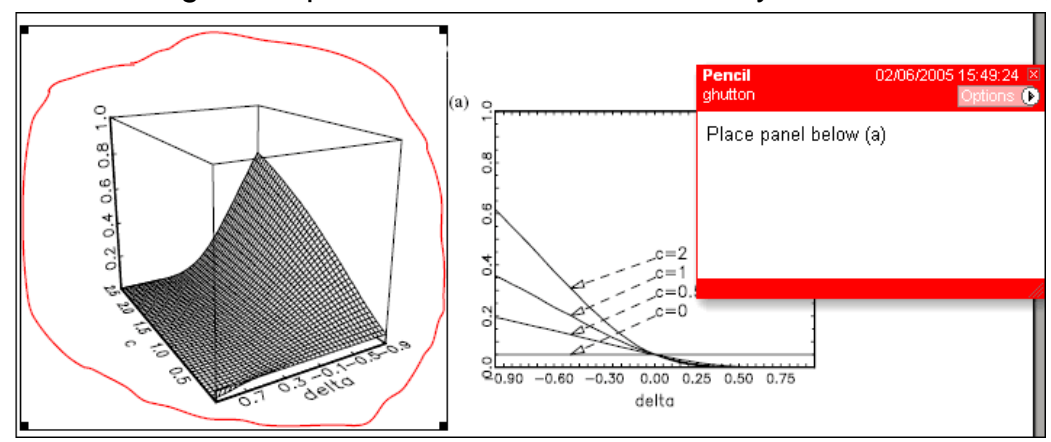

How to use it:

1. Select Tools $>$ Drawing Markups $>$ Pencil Tool

2. Draw with the cursor

3. Multiple pieces of pencil annotation can be grouped together

4. Once finished, move the cursor over the shape until an arrowhead appears and right click

5. Select Open Pop-Up Note and type in a details of required change

6. Click the $X$ in the top right hand corner of the note box to close. 
Help

For further information on how to annotate proofs click on the Help button to activate a list of instructions:

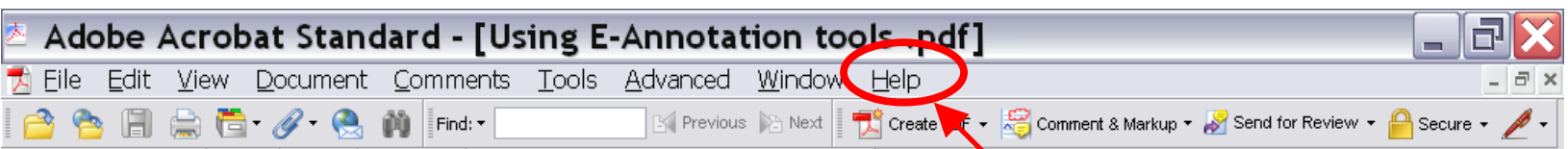

